that they felt more confident managing similar scenarios for real with three strongly agreeing. All participants either agreed or strongly agreed that the simulation study day was a realistic representation of the cases they come across in their roles, with the majority of participants strongly agreeing that the debrief was helpful. The majority of participants strongly agreed they would recommend this style of teaching to their colleagues. Free text comments were overwhelmingly positive, particularly around how realistic the scenarios were and how safe the learning environment felt.

Conclusions Simulation training in emergency palliative care scenarios for specialist palliative care nurses working within the HLT is a novel, effective and well accepted method of training.

\section{PILOT OF A REGIONAL PALLIATIVE MEDICINE SIMULATION TRAINING PACKAGE FOR INTERNAL MEDICINE TRAINING AS A SPECIALIST TRAINEE COLLABORATIVE: PEER EDUCATION, AN OPPORTUNITY FOR DUAL COMPETENCY ACHIEVEMENT}

Kerry Waterfield, Hannah Billett, Jo Brown, Felicity Dewhurst, Elizabeth Fleming, Kate Howorth, Emily Kavanagh, Rachel Kiltie, Lucy Robinson, Grace Rowley, Donna Wakefield, Elizabeth Woods, Deepta Churm, Rowan Walmsley. Health Education North East, Northumbria Healthcare NHS Foundation Trust

\subsection{6/spcare-2020-PCC.64}

Background Shape of Training is a substantial transformation to postgraduate medical education. 'Managing end of life and applying palliative care skills is one of eight 'specialty capabilities in practice' for all internal medicine trainees (IMTs). Simulation based training (SIM) can help ensure a programme of holistic and intuitive assessment (JRCPTB, 2019). As a group of palliative medicine trainees (PMTs), we developed an innovative simulation package for IMTs across the North East region. This offers an exciting opportunity for dual competency achievement: PMTs will develop their skills in management and teaching, whilst IMTs will develop palliative care knowledge, skills and attitudes required.

Methods A literature review evaluated pre-existing palliative medicine simulation training programmes. All PMTs were trained in SIM facilitation and debrief. A comprehensive review of IMT and PMT curriculum requirements was used to develop teaching materials. This was piloted at two half day training sessions attended by 11 out of 12 IMTs that commenced at Northumbria NHS trust this year.

Results Feedback from all trainees who took part in the pilot was very positive with evidence of good progress in confidence in the majority of curriculum outcomes.

Conclusion This pilot aimed to inform the development of a regional training course. Evaluation of the pilot showed its potential impact and the value of a locally delivered course. It also highlighted potential challenges in the time commitment required from a small group of PMTs. Feedback has informed a second pilot at another trust to ascertain if it is possible to deliver high quality and effective training in a more sustainable and reproducible way. We are also aiming to develop the material into a training package that could be used nationally. Palliative SIM aims to provide an efficient and effective way of improving training and patient care.

\section{4 \\ A SURVEY OF CURRENT PALLIATIVE CARE TRAINING IN UNDERGRADUATE MEDICAL, NURSING, AND ALLIED HEALTH COURSES}

Nicola White, Ollie Minton, Sarah Yardley, Linda Oostendorp, Patrick Stone. University College London, Brighton and Sussex University Hospitals NHS Trust

\subsection{6/spcare-2020-PCC.65}

Background Impending death is not well recognised. As death occurs in any setting, at any time, it is vital that all healthcare professionals, have adequate training in palliative care. The aim of the survey was to understand what current training is available on the recognition of dying at undergraduate level.

Methods A survey of the following UK undergraduate courses: medical, nursing, social work, physiotherapy, occupational therapy was completed. All courses were asked what training was provided in recognising and communication of dying and what time was dedicated to this.

Results 73/198 courses responded (37\%). 18/20 medical courses provided training in recognising dying with a median of 2 hours dedicated, and $17 / 20$ in the communication of dying with a median of 3 hours dedicated. $80 \%(43 / 54)$ of nursing and allied health professional courses provided some form of training in end-of-life care. Many of these courses expressed frustration at the lack of resources, funding, and time to include more training. Those with more time dedicated to palliative care training often had a 'champion' to advocate for it.

Conclusion Training in end-of-life care was inconsistent and variable across courses and professions. Further work on how we can facilitate training on these courses is needed.

\section{IMPLEMENTING REAL TALK: INTERPROFESSIONAL EDUCATION INTERVENTION ENABLING CLINICIANS TO DEVELOP CONFIDENCE IN OPEN AND HONEST CONVERSATIONS ABOUT DYING}

Becky Whittaker, Sharan Watson. Loughborough University, University of Derby

\subsection{6/spcare-2020-PCC.66}

Background National reports highlight the need to break down the barriers between the evidence to practice gap in talking with patients about dying. Our programme of research incorporates evidence and video clips from UK hospice consultations. Real Talk is designed to fit into existing communication skills training, disseminated across diverse interprofessional groups/settings, aiming to promote confidence and competence.

Real Talk holds great promise because:

- practicalities of short video clips ensure flexibility for practitioners to engage in detailed conversation and debate, enhancing the learning potential in any environment;

- the depth of evidence underpinning our resources helps demystify complex communication strategies, promoting confidence when talking about dying;

- clinicians using the resources span diverse professional groups and clinical settings helping promote talk in broaching dying and planning ahead with diagnostic uncertainty.

Methods Mixed methods, quantitative database, qualitative user evaluations, content validity from field notes and workshops. 